\title{
Digital Fabrication and Rapid Prototyping as a Curricular Component in Architecture and Urbanism Course: A Didactic Pedagogical Experience
}

XXIV International Conference

of the Iberoamerican Society

of Digital Graphics

Medellin | Colombia

\author{
Carla Cristina Secchi \\ Universidade Comunitária da Região de Chapecó - UNOCHAPECÓ | Brasil | \\ cah_secchi@unochapeco.edu.br \\ Luana Peroza Piaia \\ Universidade Comunitária da Região de Chapecó - UNOCHAPECÓ | Brasil | \\ luanapiaia@unochapeco.edu.br \\ Paola Avila \\ Universidade Comunitária da Região de Chapecó - UNOCHAPECÓ | Brasil | \\ paola.avila@unochapeco.edu.br \\ Luciano Perin \\ Universidade Comunitária da Região de Chapecó - UNOCHAPECÓ | Brasil | \\ luciano.perin@unochapeco.edu.br
}

\begin{abstract}
Digital technologies have transformed the stages of the Architecture and Urbanism design process, interfering in the learning method. The objective is to present the results acquired during the implementation of an undergraduate discipline, verifying evolution, method and impact on the process. These are presented through a qualitative approach and procedure classified as Case Study and Ex-post-facto. The evolution of the component is perceived over the years, positively impacting on the quality of teaching and training of students. The insertion of digital technologies in academic background reflects on the development of skills and abilities, providing new experiences and enriching the teaching.
\end{abstract}

Keywords: Architecture Teaching; Digital Fabrication; Rapid Prototyping; Design Process.

\section{INTRODUÇÃO}

A inserção de técnicas relacionadas à computação gráfica, tais como a utilização da Fabricação Digital (FD) e Prototipagem Rápida (PR) no ensino de Arquitetura e Urbanismo, vêm transformando e complementando as etapas do processo de projeto arquitetônico, interferindo diretamente no método de aprendizagem (Ryberg, Storch, Pupo, \& Medeiros, 2015). Estas tecnologias permitem, de forma rápida, a materialização de ideias, uma vez que a maquete física propicia a compreensão e percepção do projeto pelos acadêmicos, de maneira vantajosa e assertiva (Balzan, Piaia, Batistello, \& Miotto, 2015). É importante ressaltar a influência que o ateliê de arquitetura possui no processo de inovação da produção do ambiente construído, no qual grandes avanços são criados a partir do conhecimento (Secchi, 2019). Com a utilização destas tecnologias, o aluno passa a compreender melhor as etapas de realização de um projeto, e busca corrigir possíveis falhas observadas na materialização.

Com a inclusão das tecnologias digitais no campo da Arquitetura, passou-se a entender a importância da criação de maquetes e protótipos para desenvolver e compreender as propostas em suas diversas escalas, da concepção inicial ao detalhamento executivo (Pupo \& Celani, 2008). O uso das ferramentas computacionais na criação de projetos torna-se um importante aliado na compreensão da sua materialização (maquete, protótipo ou protótipo funcional), contribuindo também nos demais procedimentos relacionadas à complementação e interoperabilidade, resultando em melhores soluções na execução, podendo ser utilizada por todos os envolvidos no processo, do escritório à obra (Pupo, 2009).

A maquete possui diversas finalidades e formas de apresentação. Pode ser relacionada às etapas de concepção de um projeto, seja para estudo da criação e do processo; para avaliação e compreensão de uma estrutura; detalhamentos que identificam elementos de conforto ambiental; como também para apresentação e análise de cores, texturas, paisagismo e partido da proposta realizada (Pupo, 2009). Segundo Volpato, Ahrens, Ferreira, Petrush, Carvalho, Santos, Silva (2007), maquetes são um rascunho ou um processo experimental, com escalas reduzidas de projeto e se caracterizam como um instrumento que acompanha os demais itens de um objeto, como croquis ou detalhes conceituais, facilitando a variabilidade da concepção dos desenhos, destacando inclusive, as características marcantes de cada proposta.

Um protótipo tem a função de avaliar, ou seja, compreender a funcionalidade, ergonomia, dimensões e coerência dos materiais escolhidos (Pupo, 2009). São 
parte essencial do processo de ensino e aprendizagem, pois possibilitam a análise da forma e função, seja em uma etapa inicial do projeto ou na verificação do produto final (Volpato et al., 2007). Se caracterizam como um objeto para teste de ideias, focando no estudo da geometria, dimensionamento, resistência, observando além dos aspectos estéticos do objeto (Volpato et al., 2007).

Já o protótipo funcional apresenta um resultado mais completo em relação ao produto final. Ele retrata as características minuciosamente, revela dinâmicas da forma, busca concretizar a maioria ou todas as propriedades do objeto a ser projetado (Volpato et al., 2007). Geralmente é realizado em tamanho real, ou seja, na escala $1 / 1$ (proporção humana), apresentando o produto no processo de finalização da proposta (Volpato et al., 2007).

Para ocorrer a integração entre FD, PR e ensino, é necessário que as faculdades possuam, em sua infraestrutura, laboratórios de fabricação digital, pois são espaços que possibilitam a materialização das propostas (Pupo, 2009). Estes locais vêm sendo cada vez mais valorizados nos cursos de ensino superior, especialmente nas áreas de arquitetura e urbanismo, design e engenharias. Dado ao contínuo aprimoramento dos equipamentos, que se tornam mais fáceis e acessíveis, resta somente a especificidade na modelagem digital dos arquivos para cortes e impressão (Pupo \& Celani, 2009).

Ballerini (2018) salienta, que apesar da expansão dos laboratórios no âmbito do ensino de arquitetura, muitas vezes, é dado maior destaque às técnicas e maquinários do que a própria discussão dos seus benefícios para com a produção arquitetônica. É importante refletir sobre como a tecnologia pode beneficiar e melhorar a vida nas cidades, com aperfeiçoamento no canteiro de obras tradicional, além de possíveis impactos positivos no desenvolvimento das habitações (Ballerini, 2018). As tecnologias digitais aliadas ao ensino são capazes de auxiliar na concepção de diversos aspectos em relação aos variados tipos de projetos (Piaia, 2018), transformando a assimilação dos alunos a respeito da arquitetura e seus impactos sociais, por isso, torna-se fundamental a inserção de ferramentas atuais em sala de aula, principalmente aquelas voltadas a transpor do digital ao físico a criação dos estudantes (Luciano, Secchi, \& Vaz, 2018).

De acordo com Pupo e Celani (2009), a popularização dos sistemas digitais iniciou-se em 1980, quando os computadores passaram a se tornar mais acessíveis, propiciando aplicações no ensino e na pesquisa nas mais diversas áreas. Mas o advento das tecnologias digitais foi possível somente em 2003, pela disseminação propiciada pelo MIT (Massachusetts Institute of Technology), com a criação do Fab Lab (fabrication laboratory) MIT, do Center for Bit and Atoms MIT, sendo este o responsável pela rede global de Fab Labs que existente atualmente (Ballerini, 2018).

A FD possibilita a criação de objetos de modo tridimensional, por meio da materialização em maquinários específicos, viabilizando formas inovadoras e complexas, associando também às construções que necessitam de uma rápida produção (edificações pré-fabricadas), as quais podem ser customizadas e adaptadas ao usuário final (Caccere \& Santos, 2016).
As metodologias convencionais utilizadas em ateliê de arquitetura, nas quais o projeto acaba sendo restringido ao âmbito da representação, propiciam um distanciamento entre o design digital projetado e o canteiro de obras (Ballerini, 2018). Este contexto acaba gerando mudanças na prática do ensino e pesquisa em faculdades de arquitetura, que passam a acompanhar tendências mundiais em tecnologias CAD-CAM (Computer Aided Drawing, Computer Aided Manufacturing), como máquinas CNC (Comando Numérico Computadorizado) Router, cortadoras a laser e impressoras $3 \mathrm{D}$ - sendo as duas primeiras em método subtrativo e a última aditivo-, que retomam a relação da arquitetura com a produção física (Nishimura, Rodrigues, Botura Júnior, \& Silva, 2016).

Além de criar formas inovadoras, a FD acaba sendo utilizada, segundo Ballerini (2018), como uma estratégia pedagógica que aproxima a projetação com a materialização, permitindo novas discussões em sala de aula, ao passo que o aluno cria, fabrica e constrói o que projetou. Deste modo, se insere em ateliê de arquitetura como forma de retomar a discussão sobre o aprender fazendo e dar a devida importância à materialização da forma (Ballerini, 2018).

A prototipagem rápida, que se integra à $F D$, permite a fabricação de componentes físicos em três dimensões (3D), sejam eles protótipos, modelos ou componentes finais de uma edificação, na qual o processo de fabricação tem como princípio básico a adição de materiais por meio de sucessivas camadas planas (Volpato et al., 2007). Depois de pronto, além das diversas observações e apontamentos que podem ser feitos sobre objeto, é possível manipular e alterar qualquer elemento, conforme as necessidades do projetista, para posterior finalização do produto (Pupo \& Celani, 2008). Esta possibilidade de edição e melhoramento das propostas permite o avanço na qualidade dos projetos, pois se observa além do transcrito nos computadores, melhorando a percepção humana em relação à compreensão tridimensional (Pupo, 2009).

Essa técnica vem sendo utilizada desde meados dos anos 90, caracterizada por realizar protótipos de forma rápida e precisa, possibilitando a verificação posterior dos elementos em relação à ergonomia, durabilidade, materiais e técnica (Bruscato, Brendler, Viaro, Teixeira, \& Silva, 2013). Por utilizar o método aditivo, esta tecnologia permite realizar projetos mais complexos, com geometrias diferenciadas, podendo conter detalhes impossíveis de serem transcritos por outro processo de fabricação (Nishimura et al., 2016).

Diante do contexto apresentado, fica evidente que o uso da FD e da PR tornam-se o diferencial no campo educacional. Se inseridos nas disciplinas iniciais do curso de Arquitetura e Urbanismo, possibilitam ao aluno produzir modelos físicos que contribuem na resolução de problemas e soluções, estimulando experimentações e simulações inovadoras (Pupo \& Celani, 2009).

O artigo tem como objetivo apresentar os resultados adquiridos ao longo de cinco anos da implantação da disciplina obrigatória intitulada "Fabricação Digital e Prototipagem Rápida", da matriz curricular do curso de Arquitetura e Urbanismo da Universidade Comunitária da Região de Chapecó - UNOCHAPECÓ, verificando a evolução, o método utilizado e o impacto ocasionado no processo de projeto. Esta pesquisa é resultado do 
acompanhamento da disciplina pela professora titular desde o semestre de 2015/2, que auxiliou na fundamentação e realização da base técnica e pedagógica dos quesitos presentes na ementa desta componente curricular. Além de verificar o conteúdo produzido ao longo destes anos, objetiva-se também verificar como se deu a mudança do processo de projeto dos acadêmicos, por meio do conhecimento e aprendizado das tecnologias digitais, seus conteúdos e aplicabilidades, relacionando o uso dessas técnicas em outras disciplinas.

Deste modo, espera-se que o relato desta experiência possa colaborar para a reflexão sobre o uso das tecnologias de FD e PR no processo de ensino de Arquitetura e Urbanismo, bem como mostrar sua importância em relação à percepção e formação crítica dos acadêmicos sobre a materialização de suas ideias.

\section{METODOLOGIA}

Quanto a sua caracterização, a investigação assume abordagem qualitativa, natureza aplicada, objetivo exploratório e procedimentos de Estudo de Caso e Expost-facto. A abordagem qualitativa da investigação, de acordo com Fonseca (2002), está atrelada ao maior enfoque de aspectos como interpretação e contexto do objeto em estudo, relação próxima do autor com os eventos da pesquisa, maior intervalo de tempo e de quantidade dos dados, além de possuir o ponto de vista do pesquisador internamente aos acontecimentos. A natureza aplicada do estudo é definida por gerar novos conhecimentos por meio da aplicação prática (Silveira \& Córdova, 2009). Já o objetivo exploratório, é compreendido a partir do fato de que a pesquisa propicia maior aproximação ao problema estudado, envolvendo principalmente estudo de caso (Gil, 2017). A investigação assume o procedimento de Estudo de Caso, que, de acordo com Gil (2017), é caracterizado por tratar de uma entidade bem estabelecida e única, que pode ser um sistema educativo, neste caso, a disciplina de "Fabricação Digital e Prototipagem Rápida”. A intenção é evidenciar o estudo de caso tal como é percebido pelos pesquisadores, descrevendo as características essenciais que o tornam um modelo de estudo (Gil, 2017). Além deste procedimento, a pesquisa pode ser definida como Ex-postfacto, pois busca identificar as relações de causa e efeito que ocorrem após o evento (Fonseca, 2002), que neste caso, é a verificação de sua evolução ao longo dos anos, as mudanças de métodos e o impacto ocasionado no processo de projeto do aluno.

Deste modo, a pesquisa é desenvolvida em dois momentos: a) Levantamento e organização dos dados e produção da disciplina ao longo dos anos de sua realização; b) Análise e verificação da transformação e evolução, ao longo dos semestres, dos métodos, ferramentas e maquinários utilizados (Figura 1).

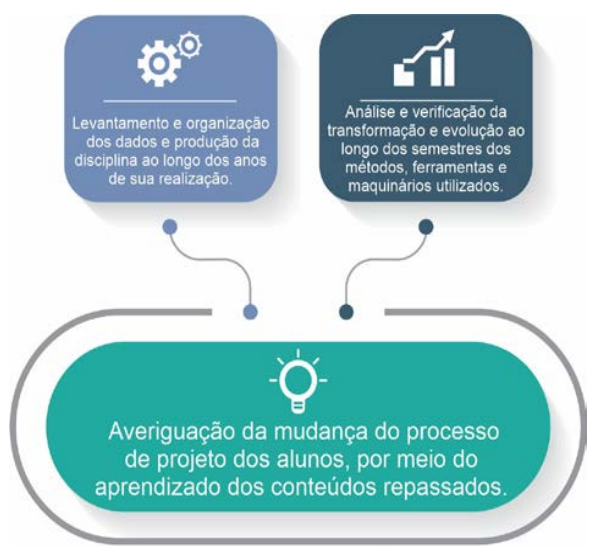

Figura 1: Representação das etapas do estudo. Fonte: Freepik, adaptado pelos autores (2020).

\section{A DISCIPLINA}

Com o passar dos anos, a computação gráfica mostrou grande evolução, deixando para trás a rigidez e o método manual de projetar, desencadeando na reformulação dos processos a partir do uso das tecnologias digitais, criando ambientes virtuais que trazem a possibilidade de novas experimentações, mais rápidas e eficazes (Pupo, 2009). Com o uso destes novos métodos, a criação de formas complexas pode ser testada, avaliada e materializada, durante todo o processo de projeto.

No ano de 2013, a Unochapecó foi escolhida dentre outras IES do estado de Santa Catarina, para implantar o Laboratório Pronto 3D Chapecó. Com a inserção deste espaço, que visa o uso de tecnologias digitais orientadas ao 3D, o curso de Arquitetura e Urbanismo da mesma IES, alterou seu foco para o ensino voltado às questões tecnológicas. Dessa forma, em 2014, o Plano Pedagógico de Curso (PPC), foi alterado e uma nova matriz curricular criada, de modo a valorizar a inserção das tecnologias digitais e destacar a inovação no ensino de cada componente. Foi implementada a disciplina de "Fabricação Digital e Prototipagem Rápida" como componente obrigatória, além de outras de Desenho Arquitetônico com enfoque no ensino da tecnologia BIM (Building Modeling Information) desde o primeiro período. É importante ressaltar que as tecnologias de fabricação digital e BIM fazem parte de toda a reestruturação metodológica realizada pelo curso, sendo encaradas como ferramentas primordiais ao longo de todo o processo de projeto.

A disciplina de "Fabricação Digital e Prototipagem Rápida" foi idealizada para acontecer no $3^{\circ}$ período do curso, e as aulas da primeira turma ocorreram no semestre de 2015/1, tendo como aporte as disciplinas de Desenho Arquitetônico (realizadas no $1^{\circ}$ e $2^{\circ}$ período, respectivamente), nas quais são repassados os conhecimentos tecnológicos em software específico para a inserção da tecnologia BIM. Essas alterações evidenciam o fato de a estrutura do curso estar pautada no uso de ferramentas digitais, que, por estarem presentes desde o início, podem ser aplicadas nas demais disciplinas ao longo da graduação, integrando toda a base curricular.

Consta no Plano de Ensino da disciplina em questão, a Ementa Curricular, a qual aborda: "Conceitos de modelo, 
maquete e protótipo. Fabricação Digital. Prototipagem Rápida. Modelagem Paramétrica. Tipos de materiais. Tecnologias de digitalização 3D. Geometria Descritiva Aplicada". Esta componente possui o total de quatro créditos semanais, totalizando 80 horas por semestre. Destaca-se o objetivo geral, pautado em assegurar ao acadêmico o conhecimento acerca do potencial da Fabricação Digital e da Prototipagem Rápida para aplicação no processo de projeto de Arquitetura e Urbanismo. Ela auxilia diretamente nas componentes de projeto arquitetônico, nas quais a fabricação e a prototipagem fazem parte do processo de projeto, contribuindo diretamente na formação de profissionais aptos a trabalhar e utilizar no dia a dia estas tecnologias e seus processos. Fica nítida a preocupação em explorar todas as potencialidades que a FD e PR possuem, principalmente quando estas estão relacionadas ao desenvolvimento de modelos virtuais e físicos, auxiliando na criação, desenvolvimento e materialização de um projeto.

A inserção desta disciplina nos primeiros semestres do curso permite aos acadêmicos maior conhecimento de materiais e técnicas necessárias para realizar a materialização da forma, bem como, possibilita desenvolver modelos tridimensionais complexos com o auxílio da modelagem paramétrica, grande aliada na fração tecnológica do processo de projeto. Nesse sentido, torna-se indispensável desenvolver nos acadêmicos competências e habilidades que visem o pensamento crítico e criativo, permitindo trabalhar com as inúmeras possibilidades que as tecnologias de FD e PR podem oportunizar.

A metodologia das aulas baseia-se em três momentos: teórico; teórico/prático e prático, realizados em laboratório de informática e em laboratório de fabricação digital. $\mathrm{Na}$ parte teórica, os conteúdos são apresentados por meio do auxílio de recursos audiovisuais. São repassados conceitos de modelo, maquete e protótipo aplicados no processo de projeto; a importância de compreensão da Geometria Descritiva aplicada na FD; os panoramas nos quais as tecnologias e ferramentas computacionais auxiliam no processo da produção arquitetônica; os tipos de materiais; os maquinários existentes no laboratório de fabricação digital; e a importância que a PR e a modelagem paramétrica exercem na criação de formas complexas, que podem atuar como o diferencial em cada projeto realizado.

$\mathrm{Na}$ realização do processo teórico/prático, são apresentados e discutidos os principais softwares relacionados às temáticas que permeiam a disciplina. São realizados exercícios aplicados, nos quais os alunos desenvolvem suas atividades e avaliações por meio da utilização destes programas. Vários softwares foram ensinados aos acadêmicos ao longo destes 5 anos, destacam-se: Revit (Autodesk), Slicer for Fusion 360 antigo 123-D Make (Autodesk), Pepakura Design 3, Corel Draw, AutoCAD (Autodesk), Rhinoceros 5.0 e 6.0, e o plugin Grasshopper. A partir do aprendizado de tais programas, os acadêmicos realizam a modelagem de modelos tridimensionais, planificando-os para posterior manufatura.

As aulas práticas são realizadas no laboratório Pronto 3D Chapecó. Neste local, os acadêmicos realizam a prototipagem das atividades desenvolvidas em sala de aula. Utilizam-se os seguintes equipamentos: cortadora a laser, impressora 3D e maquinário CNC Router.

Por se tratar de uma disciplina inovadora, tendo na época de implantação poucos exemplos nos quais se basear, é compreensível que esta sofreu modificações ao longo dos semestres. Essas mudanças tiveram impacto significativo no aprendizado do aluno, pois alterou-se a forma de abordagem no quesito "softwares", visto que a variedade de programas repassados durante um semestre sobrecarregava a disciplina, pois não havia tempo hábil para os acadêmicos desenvolverem as atividades e avaliações necessárias, assim como fixar o aprendizado. Com isso, alguns programas foram retirados do cronograma (Pepakura Design 3 e AutoCAD), e outros inseridos (Corel Draw). O maquinário permaneceu 0 mesmo neste período, mas novas avaliações e atividades foram criadas, possibilitando o surgimento de questionamentos acerca das temáticas abordadas e um melhor aproveitamento do conhecimento adquirido por parte dos acadêmicos.

\section{RESULTADOS E DISCUSSÕES}

Foram desenvolvidos projetos, modelos e protótipos para vários usos, em diversas escalas, utilizando materiais como: MDF (Medium-Density Fiberboard ou Placa de fibra de média densidade) de espessura $18 \mathrm{~mm}, 15 \mathrm{~mm}$ e $3 \mathrm{~mm}$; EVA (Etil Vinil Acetato) $2 \mathrm{~mm}$, filamento PLA (Ácido Polilático); compensado flexível $6 \mathrm{~mm}$; e OSB (Oriented Strand Board) $15 \mathrm{~mm}$. Estes insumos foram utilizados nos equipamentos disponíveis no laboratório, os quais já foram mencionados. Transcreve-se abaixo as atividades realizadas ao longo de cada semestre, apresentando os processos e produtos desenvolvidos pelos alunos, em ordem cronológica, por meio de imagens:

- 2015/1: Realização de quatro atividades avaliativas: modelagem 3D e planificação de um terreno na escala 1/100; modelagem 3D e planificação de um mobiliário para estudo na escala $1 / 1$; modelagem $3 \mathrm{D}$, fatiamento e planificação de uma cadeira na escala 1/10; modelagem 3D, fatiamento e planificação de uma cobertura orgânica na escala 1/200. Os softwares utilizados foram: Revit, AutoCAD, Pepakura Design, 123D Make, Rhinoceros e Grasshopper. Não se tem relatos fotográficos deste semestre, pois a disciplina foi ministrada por outro docente. Destaca-se que não foi realizada nenhuma atividade na Impressora $3 \mathrm{D}$, pois esta ainda não fazia parte dos maquinários do laboratório.

- 2015/2: No período seguinte, permaneceram as quatro atividades avaliativas e os respectivos softwares já mencionados, alterando somente a sua disposição ao longo do processo. Sendo realizadas da seguinte forma: modelagem 3D, fatiamento e planificação de uma cadeira na escala 1/10; modelagem 3D e planificação de um terreno na escala 1/100; modelagem 3D, fatiamento e planificação de uma cobertura orgânica na escala 1/200 e modelagem 3D e planificação de um mobiliário para estudo na escala 1/1. A Figura 2 mostra os resultados obtidos. 


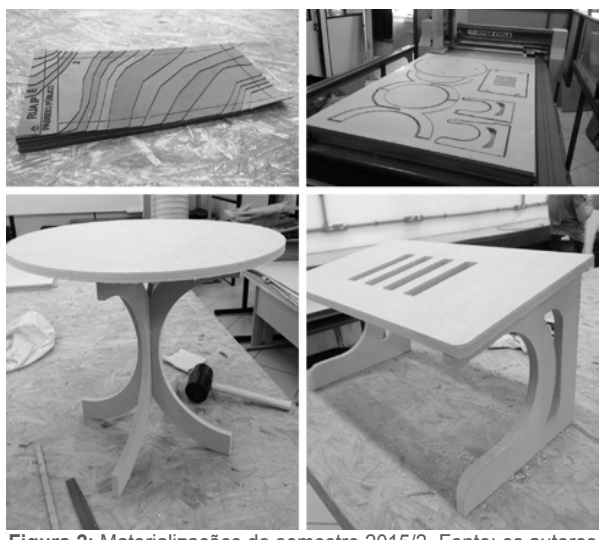

Figura 2: Materializações do semestre 2015/2. Fonte: os autores (2020).

- 2016/1: Neste semestre foram realizadas cinco atividades avaliativas: modelagem $3 \mathrm{D}$ e planificação de um terreno na escala 1/100; modelagem 3D, fatiamento e planificação de uma cobertura orgânica na escala 1/200; modelagem 3D, fatiamento e planificação de um mobiliário (cadeira) na escala 1/10; modelagem 3D, fatiamento e planificação de um mobiliário na escala 1/1; e um protótipo de edifício em altura, na escala 1/200. Deixou-se de utilizar o software Pepakura Design e incluiu-se a utilização da Impressora 3D, adquirida pelo curso. A Figura 3 mostra os resultados obtidos no semestre.
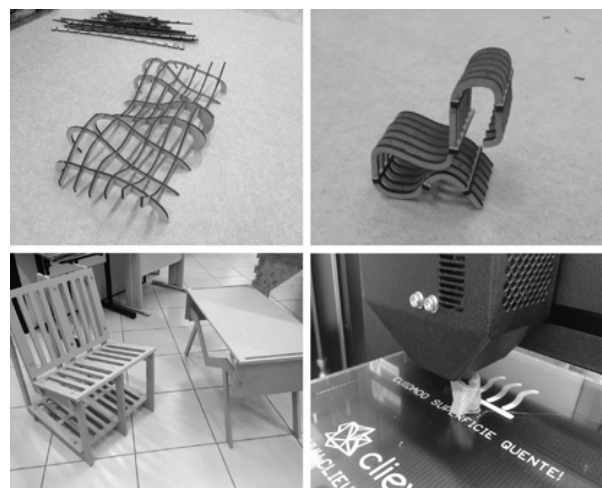

Figura 3: Materializações do semestre 2016/1. Fonte: os autores (2020).

- 2016/2: Com relação ao semestre 2016/2, quatro avaliações permaneceram iguais ao semestre anterior. A mudança ocorreu na avaliação cinco, que ao invés de imprimir na impressora 3D um protótipo de um edifício em altura, foram impressas plantas baixas de residências, na escala 1/100. Os softwares utilizados continuam os mesmos. A Figura 4 mostra os resultados obtidos no processo.

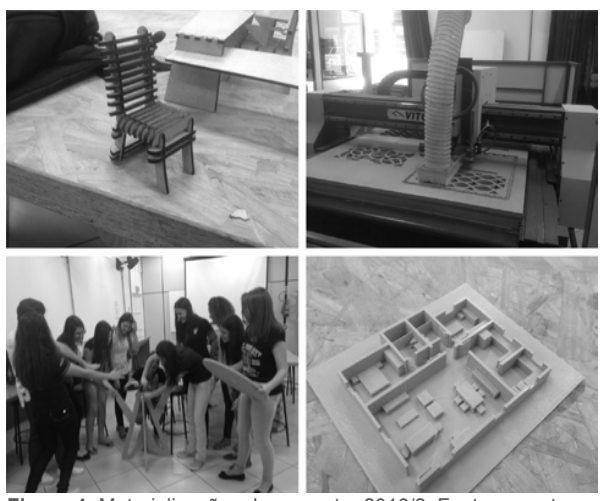

Figura 4: Materializações do semestre 2016/2. Fonte: os autores (2020).

- 2017/1: Neste semestre, o número de atividades avaliativas permanece o mesmo. Destaca-se que, o mobiliário concebido na escala $1 / 1$ foi projetado pensando no uso para outro laboratório do curso na universidade. Além disso, ao invés das plantas baixas, foram impressos em 3D cortes técnicos de uma residência de 2 pavimentos. Não houve alteração no quadro de softwares. A Figura 5 mostra os resultados obtidos no processo.
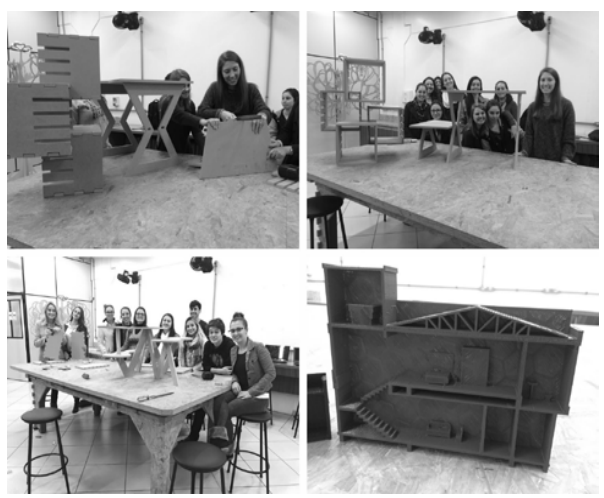

Figura 5: Materializações do semestre 2017/1. Fonte: os autores (2020).

- 2017/2: Três atividades permanecem iguais: modelagem 3D e planificação de terreno na escala 1/100; modelagem 3D, fatiamento e planificação de uma cobertura orgânica na escala 1/200; e modelagem 3D, fatiamento e planificação de um mobiliário na escala 1/1. Duas são alteradas: modelagem 3D e planificação de plantas baixas residenciais, atividade em conjunto com outra disciplina do curso; e modelagem e impressão 3D de mobiliário interno residencial. A Figura 6 mostra os resultados obtidos no semestre. 

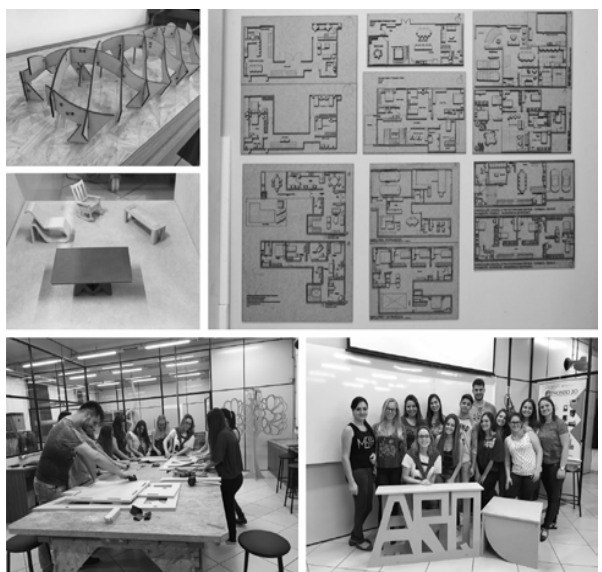

Figura 6: Materializações do semestre 2017/2. Fonte: os autores (2020).

- 2018/1: Neste semestre permanecem as cinco avaliações, porém com alterações, das quais destaca-se: modelagem 3D e planificação de um terreno na escala 1/100; modelagem 3D, fatiamento e planificação de um mobiliário na escala $1 / 10$; modelagem $3 \mathrm{D}$, fatiamento e planificação de um mobiliário na escala 1/1; modelagem 3D e planificação de cortes técnicos de uma residência de dois pavimentos; e Modelagem e impressão 3D de ambientes internos residenciais, na escala 1/20. A Figura 7 mostra os resultados obtidos no processo.
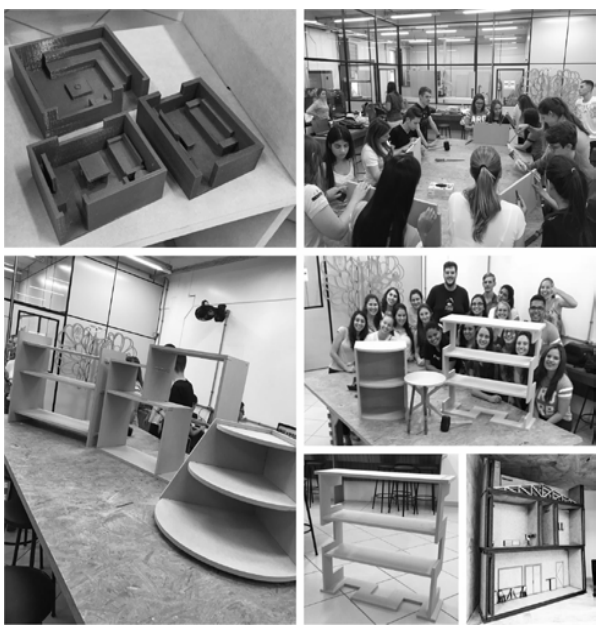

Figura 7: Materializações do semestre 2018/1. Fonte: os autores (2020).

- 2018/2: Devido ao número de alunos deste semestre, resolveu-se diminuir o número de atividades para quatro, sendo elas: modelagem 3D e planificação de um terreno na escala 1/100; modelagem 3D, fatiamento e planificação de um mobiliário na escala 1/10; modelagem $3 \mathrm{D}$, fatiamento e planificação de uma escultura interativa na escala 1/1; e modelagem e impressão 3D de luminárias, na escala $1 / 1$. O grande diferencial deste semestre foi a utilização de sobras de material, que os alunos eram responsáveis por aproveitar na realização da atividade das esculturas interativas. A Figura 8 mostra os resultados obtidos no processo.

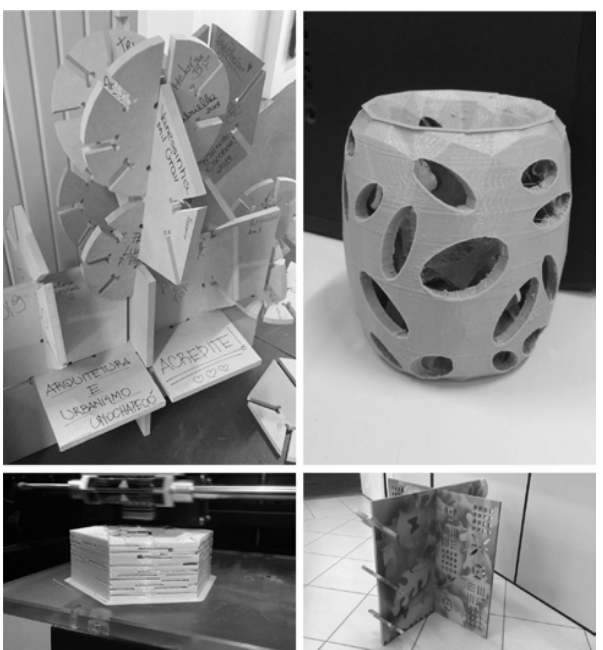

Figura 8: Materializações do semestre 2018/2. Fonte: os autores (2020).

- 2019/1: Para este semestre, optou-se pela realização de uma atividade diferenciada, de modo a aproximar ainda mais o acadêmico das tecnologias digitais. Deste modo, foi desenvolvido um mobiliário urbano na escala $1 / 1$, utilizando o sistema construtivo WikiHouse versão 3.0. Além desta atividade, foram desenvolvidas mais quatro: modelagem $3 \mathrm{D} e$ planificação de um terreno na escala 1/100; modelagem 3D, fatiamento e planificação de um mobiliário na escala 1/10; modelagem 3D, fatiamento e planificação de um mobiliário na escala 1/1; e modelagem e impressão 3D de um edifício, na escala 1/20. A Figura 9 mostra os resultados obtidos no processo.
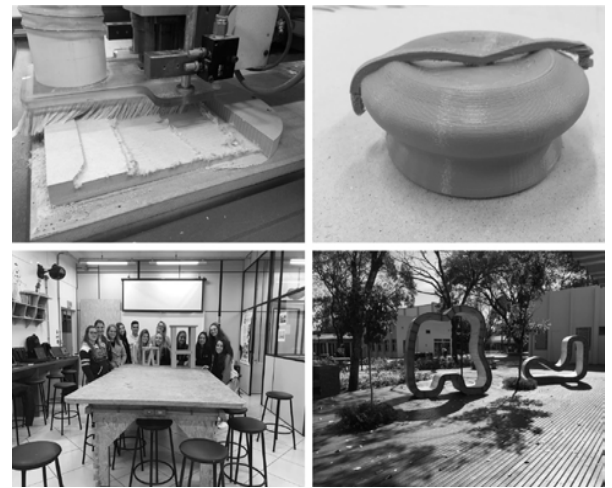

Figura 9: Materializações do semestre 2019/1. Fonte: os autores

(2020).

- 2019/2: Neste semestre, optou-se por quatro atividades avaliativas: modelagem 3D e planificação de um terreno na escala 1/100; modelagem 3D, fatiamento e planificação de luminárias na escala 1/1; modelagem e impressão 3D de ambientes internos residenciais; e modelagem 3D e planificação de um mobiliário urbano na escala 1/1. O destaque fica por conta da luminária 
realizada na escala real, que instigou os acadêmicos a compreender além dos encaixes, e montar a parte elétrica do objeto. A Figura 10 mostra os resultados obtidos no processo.
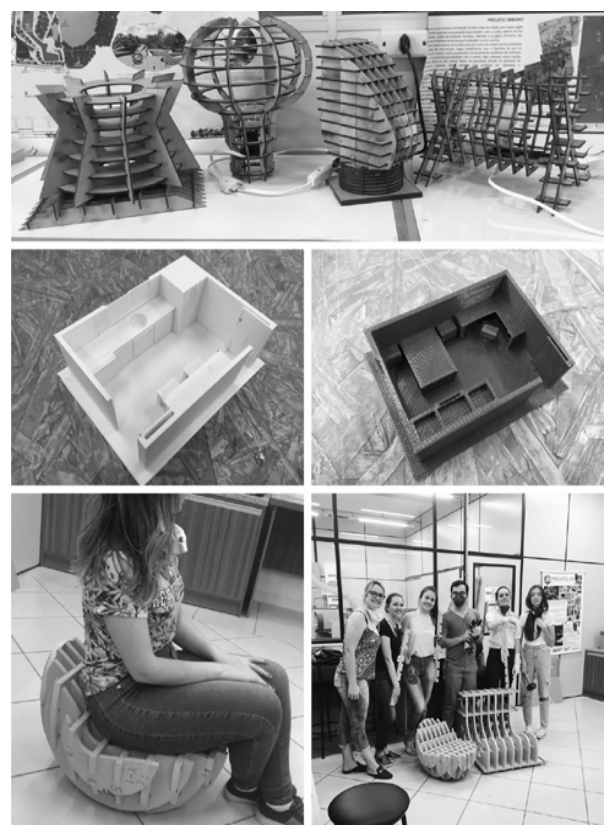

Figura 10: Materializações do semestre 2019/2. Fonte: os autores (2020).

- 2020/1: As aulas deste semestre foram realizadas de forma remota síncronas, por conta da pandemia de coronavírus (COVID-19). Deste modo, a materialização das atividades ainda não aconteceu. Espera-se que até o final do ano os alunos possam prototipar seus projetos, que foram realizados por meio de quatro avaliações, tendo como destaque: modelagem 3D, fatiamento e planificação de um mobiliário, podendo exercer mais de uma função, na escala 1/10; e a modelagem 3D e planificação de um mobiliário urbano na escala $1 / 1$, contendo conceito, diretrizes conceituais e um painel moodboard. Neste período, foi inserida a aprendizagem no software Corel Draw e descontinuado o uso do AutoCAD, por conta da facilidade de entendimento do novo programa, além das ferramentas que podem ser utilizadas pelos acadêmicos em outras disciplinas.

Fica evidente a evolução e a transformação do componente curricular ao longo dos anos, havendo aprimoramento da metodologia empregada, técnicas, atividades, softwares e maquinários que foram introduzidos no programa de aprendizagem, impactando nas competências estudantis ao fim de cada semestre. O desenvolvimento e materialização de todas as etapas do processo de projeto, desde a topografia do terreno, até o mobiliário interno, além da integração com demais componentes curriculares do curso, permite refletir acerca dos métodos que são utilizados atualmente para o ensino de Arquitetura e Urbanismo.

A verificação da mudança do processo de projeto dos alunos, por meio do aprendizado de tais conteúdos, é vista quando relaciona-se a disciplina de "Fabricação Digital e
Prototipagem Rápida" com as demais componentes do curso. Diversas atividades descritas acima são realizadas de forma integrada, associando o conteúdo e objeto a ser desenvolvido com as componentes curriculares presentes no $3^{\circ}$ período. Como exemplo, a modelagem e protótipo do terreno está relacionada a disciplina de Projeto Arquitetônico III, já a modelagem e protótipo de uma cadeira na escala $1 / 10$, relaciona-se com a disciplina de Projeto de Arquitetura de Interiores I. Além disso, os alunos utilizam os ensinamentos repassados para realizar a materialização de maquetes, estudos topográficos e outros modelos durante toda a caminhada acadêmica e em diferentes etapas do processo de projeto, seja de forma avaliativa ou de representação, melhorando o entendimento de seus projetos. Proporcionar ao acadêmico a materialização de suas ideias contribui de maneira significativa em sua formação. A avaliação de erros e assertividades na execução de um protótipo antes de sua produção final alcança ricos ensinamentos no processo de aprendizagem do aluno.

\section{CONCLUSÃO}

$\mathrm{O}$ aprendizado acerca das tecnologias reflete não somente no período de realização da disciplina, mas em toda a formação do aluno ao longo do curso, acarretando na interdisciplinaridade e no aprimoramento da concretização de ideias. A disciplina impacta diretamente na qualidade do ensino e na formação cognitiva do estudante, oportunizando novas experiências, técnicas e habilidades. As tecnologias potencializam a produção, o gerenciamento e a compreensão espacial da arquitetura e do ambiente construído, atuando no desenvolvimento desde protótipos a produtos finais, com precisão e eficiência. É nesse sentido que o propósito da educação e das tecnologias é alcançado.

Desta forma, o uso da fabricação digital e prototipagem rápida, aliada ao Laboratório Pronto 3D Chapecó, inserido na IES Unochapecó, demonstra ir muito além de uma simples técnica de materialização de maquetes. A inserção destas tecnologias ao ensino de Arquitetura e Urbanismo, estimula o pensamento crítico e cognitivo do aluno desde a criação e materialização de projetos em escala real, até protótipos apresentados em escala reduzida. Faz-se com que o aluno compreenda e reflita a respeito de todas as interferências sobre as quais o projeto está submetido, para então poder realizar a sua fabricação final.

Com a possibilidade de criar, preparar os arquivos para manufatura e fabricar o objeto, os acadêmicos compreendem na íntegra todos os passos necessários para realização da materialização de suas ideias, percebendo os erros e incompatibilidades que ocorrem quando o processo não é realizado da forma correta. 0 incentivo à mudança no processo de projeto, instigando o aluno a ousar e inovar são fundamentais para a permanência destas tecnologias no dia a dia de uma Faculdade de Arquitetura e Urbanismo. Portanto, é fundamental que aconteça a implantação destas disciplinas, com olhar voltado às práticas inovadoras. Assim, é preciso entender e discutir as potencialidades que a FD e PR têm e podem exercer nos aspectos didáticopedagógicos, para então transformar a metodologia de ensino. 


\section{REFERÊNCIAS}

Ballerini, F. (2018). Fabricação Digital e Arquitetura: Para Além da Superespecialização dos Arquitetos em Direção à Colaboração. Pixo - Revista De Arquitetura, Cidade E Contemporaneidade, 2.

Balzan, K. L., Piaia, L. P., Batistello, P., \& Miotto, J. (2015). Prototipagem rápida e fabricação digital em ateliê vertical: do processo à materialização. Paper presented at the SIGraDi Florianópolis, Brasil. doi:10.5151.

Bruscato, M. U.; Brendler, C. F.; Viaro, F. S.; Teixeira, F. G.; Silva, R. P. (2013). Uso da fabricação digital e prototipagem no desenvolvimento do projeto de produto: análises de simulações digitais. Paper presented at the SIGraDi São Paulo, Brasil. doi:10.5151.

Caccere, J. P., Santos, A. D. (2016). Sustentabilidade no projeto e manufatura de produtos através da fabricação Digital. Paper presented at the $12^{\circ}$ Congresso Brasileiro de Pesquisa e Desenvolvimento em Design São Paulo. doi: 10.5151.

Fonseca, J. J. S. (2002). Metodologia da pesquisa científica. Fortaleza: UEC

Gil, A. C. (2017). Como elaborar projetos de pesquisa. (Vol. 6 ). Rio de Janeiro: Atlas.

Luciano, P. T., Secchi, C. C., \& Vaz, C. E. V. (2018). Animation and Prototyping as Tools for Teaching Project in Architecture. Paper presented at the SIGraDi São Paulo, Brasil. doi:10.5151.

Nishimura, P. L. G., Rodrigues, O. V., Botura Júnior, G., Silva, L. A. d. (2016). Prototipagem Rápida: Um Comparativo entre uma Tecnologia Aditiva e uma Subtrativa. Paper presented at the Congresso Brasileiro de Pesquisa e Desenvolvimento em Design Belo Horizote, MG.

Piaia, L. P. (2018). Ferramentas computacionais na análise de projetos de Habitação de Interesse Social. (Dissertação Mestrado). Universidade Federal de Santa Catarina, Florianópolis.

Pupo, R. T. (2009). Inserção da prototipagem e fabricação digitais no processo de projeto: um novo desafio para o ensino de arquitetura. (doutorado). Universidade Estadual de Campinas, Campinas, SP

Pupo, R. T., \& Celani, G. (2008). Implementando a fabricação digital e a prototipagem rápida em cursos de arquitetura: dificuldades e realidade. Paper presented at the SIGraDi, Cuba.

Pupo, R. T., \& Celani, G. (2009). TÉCNICAS DE PROTOTIPAGEM DIGITAL PARA ARQUITETURA. Paper presented at the Graphica'09, Rio de Janeiro, Brasil.

Ryberg, M. C., Storchi, M., Pupo, R., \& Medeiros, I. d. (2015). A fabricação digital como ferramenta de processo de projeto: conectando design e arquitetura. Paper presented at the SIGraDi São Paulo, Brasil. doi:10.5151.

Secchi, C. C. (2019). Arquitetura Open Source: Capacitação, Criação e Materialização com Suporte da Fabricação Digital. (Dissertação Mestrado). Universidade Federal de Santa Catarina, Florianópolis.

Silveira, D. T., \& Córdova, F. P. (2009). UNIDADE 2 - A PESQUISA CIENTÍFICA. In E. d. UFRGS (Ed.), Métodos de pesquisa (pp. 31-42)

Volpato, N. Ahrens, H. C., Ferreira, C. V., Petrush, G., Carvalho, J., Santos, J. R. L., Silva, J. V. L. (2007). Prototipagem Rápida: Tecnologias e aplicações. São Paulo: Blucher. 